\title{
Caminhos de axé na busca por cuidado: uma análise preliminar da experiência de crise de adeptos do Candomblé em processo de desinstitucionalização em saúde mental
}

\author{
I ${ }^{1}$ Clarice Moreira Portugal, ${ }^{2}$ Monica de Oliveira Nunes, \\ ${ }^{3}$ Maria Fernanda Cruz Coutinho I
}

Resumo: O artigo objetivou abordar o acolhimento à experiência da crise em saúde mental a partir da cartoetnografia dos territórios existenciais e das práticas cotidianas de cuidado de adeptos do Candomblé em processo de desinstitucionalização em saúde mental de Salvador (BA) e adjacências. Para esses fins, nos valemos da abordagem teóricometodológica cartoetnográfica. A pesquisa envolveu entrevistas não estruturadas conjugadas à observação participante nos moldes etnográficos nos espaços da vida cotidiana dos participantes. A análise de dados baseou-se em categorias éticas voltadas para o processo de desinstitucionalização e em uma segunda leitura amparada no que propusemos como "matriz cartoetnográfica de linhas de pensamento". Verificamos que a experiência de crise se mostra bastante presente nas trajetórias dos interlocutores, cujas marcas são a interrupção do cotidiano, sua valoração moral e a convocação (por vezes tácita) da rede de apoio. Do ponto de vista narrativo, os atendimentos em pronto atendimentos e/ou emergências psiquiátricas são simbolicamente esvaziados e mesmo foracluídos, enquanto o acolhimento nos terreiros é simbolicamente rico e abre margem para outras interpretações e (re)criaçóes da existência; isso aponta para sua importância enquanto instituiçóes que podem contribuir para a desinstitucionalização em saúde mental daqueles que a elas recorrem.

> Palavras-chave: cartoetnografia; crise; saúde mental; cuidado; desinstitucionalização.

\author{
1 Instituto de Saúde Coletiva, \\ Universidade Federal da \\ Bahia. Salvador-BA, Brasil \\ (clariceportugal@gmail.com). \\ ORCID: 0000-0003-0373-4141 \\ 2 Instituto de Saúde Coletiva \\ Universidade Federal da \\ Bahia. Salvador-BA, Brasil \\ (monicatorrente11@gmail.com). \\ ORCID: 0000-0002-5905-4199 \\ ${ }^{3}$ Escola Nacional de Saúde \\ Pública, Fundação Oswaldo \\ Cruz. Rio de Janeiro-RJ, Brasil \\ (fernandacruzcoutinho@gmail.com). \\ ORCID: 0000-0001-7998-920X
}

Recebido em: 22/01/2019 Revisado em: 12/07/2019 Aprovado em: 12/09/2019 


\section{Introdução}

O presente artigo é produto de uma tese de doutorado (PORTUGAL, 2018), cujo objetivo consistiu em elaborar uma cartoetnografia (PORTUGAL; NUNES, 2015) dos territórios existenciais e das práticas de cuidado de candomblecistas que padecem de transtornos mentais e que conjugam em seu itinerário terapêutico o acolhimento nos terreiros e nos serviços públicos de saúde mental. Discutiremos aqui a problemática da crise, em termos dos elementos que a definem enquanto experiência, bem como sua conexão ao processo de desinstitucionalização em saúde mental e seu acolhimento nos terreiros.

A crise, geralmente, é a porta de entrada no circuito da saúde mental, o que se utiliza como fundamento principal da loucura e dá argumento à rotulação de periculosidade, à estigmatizaçáo, ao isolamento e, muitas vezes, à causa e continuidade de internaçôes compulsórias (NUNES; TORRENTÉ, 2009).

Dell'Acqua e Mezzina (1991) concebem a crise enquanto uma situação que envolva pelo menos três desses cinco elementos: gravidade da sintomatologia psiquiátrica; gravidade na ruptura familiar e/ou social; recusa ao tratamento; recusa ao contato; e situaçôes de alarme no contexto de vida cotejada à incapacidade pessoal de afrontá-las. Tal definição, ainda assim, deixa pouco clara a dimensão subjetiva dessa experiência (FERIGATO; ONOCKO-CAMPOS; BALLARIN, 2007).

Abordaremos a crise psíquica enquanto algo pertencente ao mundo da vida dos participantes; com manifestaçóes e expressóes singulares e que póe em ação fluxos de cuidado em diversas instâncias. Exporemos ainda como incide na vida de nossos interlocutores um processo de foraclusão das experiências de crise e como a imersão no Candomblé oferece subsídios à gênese de novas protonarrativas sobre seu padecer, contribuindo para um deslocamento da posição silenciada que por vezes se impóe aos portadores de sofrimento psíquico.

\section{Metodologia}

Nosso estudo pautou-se na abordagem cartoetnográfica (PORTUGAL; NUNES, 2015), que trata de acompanhar processos socioexistenciais, considerando a interpenetrabilidade de posiçôes e agenciamentos na (des)construção de mundos e modos de existência. Dessa forma, permite adentrar os diferentes settings culturais, 
terapêuticos e existenciais, sem negligenciar a densidade do componente étnicocultural em questão.

Deleuze e Guattari (2007) concebem a cartografia como um dos princípios do rizoma que reflete a compreensão de um sistema sempre aberto à diferença e à multiplicidade, sem que o processo como um todo perca sua organicidade. A cartografia, portanto, teria como norte a premissa da segmentação espacial e social do vivido, cujas linhas se entrelaçam e dão origem aos territórios.

Suas afinidades com o método etnográfico dizem respeito à abertura constante aos signos e referenciais. Além disso, conjugam-se aqui à perspectiva de Tim Ingold, que, por uma via distinta, critica a cartografia em seu sentido canônico, contrapondo-a a uma concepção da cartografia como um descobrir-caminho (INGOLD, 2005). Ao se imbricar nesse descobrir-caminho, apreende-se o mundo, em um processo de alinhamento entre os movimentos do sujeito no mundo e a resposta do mundo a eles.

Tomando isso por base, fizemos uso na construção do campo empírico de entrevistas não estruturadas conjugadas à observação participante nos moldes etnográficos, com duração de aproximadamente dois anos. Participaram do trabalho quatro interlocutores-chave (Bárbara, Jorge, Lázaro e Candelária) e diversos interlocutores-satélites (pessoas da rede de referência e demais informantes), todos identificados com pseudônimos.

O acompanhamento de casos teve como princípio norteador a análise dos itinerários terapêuticos e modos de fazer do cotidiano dessas pessoas. Todos os casos encontram-se há mais de dois anos em tratamento e viveram o fenômeno da porta giratória em emergências psiquiátricas. Ainda que dois deles não tenham passado por uma internação propriamente dita, todos foram submetidos ao engendramento de uma carreira na doença mental (GOFFMAN, 1961) em um dispositivo médico, cujas repercussóes se permitem apreender em suas vidas até hoje.

Por dizer respeito a uma rede de relaçôes, a etnografia pode exigir a análise da circulação de significados culturais, objetos e identidades. Por isso, abordamos os múltiplos contextos que conformam os territórios existenciais de nossos interlocutores, procurando dar voz aos conflitos e repercussôes sociopolíticas de suas experiências de saúde-doença.

A análise do material empírico se deu inicialmente a partir de categorias éticas elaboradas no âmbito da pesquisa maior. Predefinimos dimensôes de análise que foram desmembradas em categorias analíticas dos processos de desinstitucionalização 
(NICÁCIO, 1990; LEAL; DELGADO, 2007). Essas dimensões constituíram uma primeira matriz analítica no programa de análise de dados qualitativos NVivo 8.0 por meio do qual categorizamos as transcriçóes de entrevista e diários de campo. Ao cabo desse processo, o software emitiu relatórios específicos de cada uma das dimensóes supracitadas, cotejando-as com o material empírico bruto.

Secundariamente, esses relatórios foram lidos a partir de "matriz cartoetnográfica de linhas de pensamento", articulando em nossa análise alguns conceitos que serão abordados a seguir.

Figura 1. Matriz cartoetnográfica de linhas de pensamento

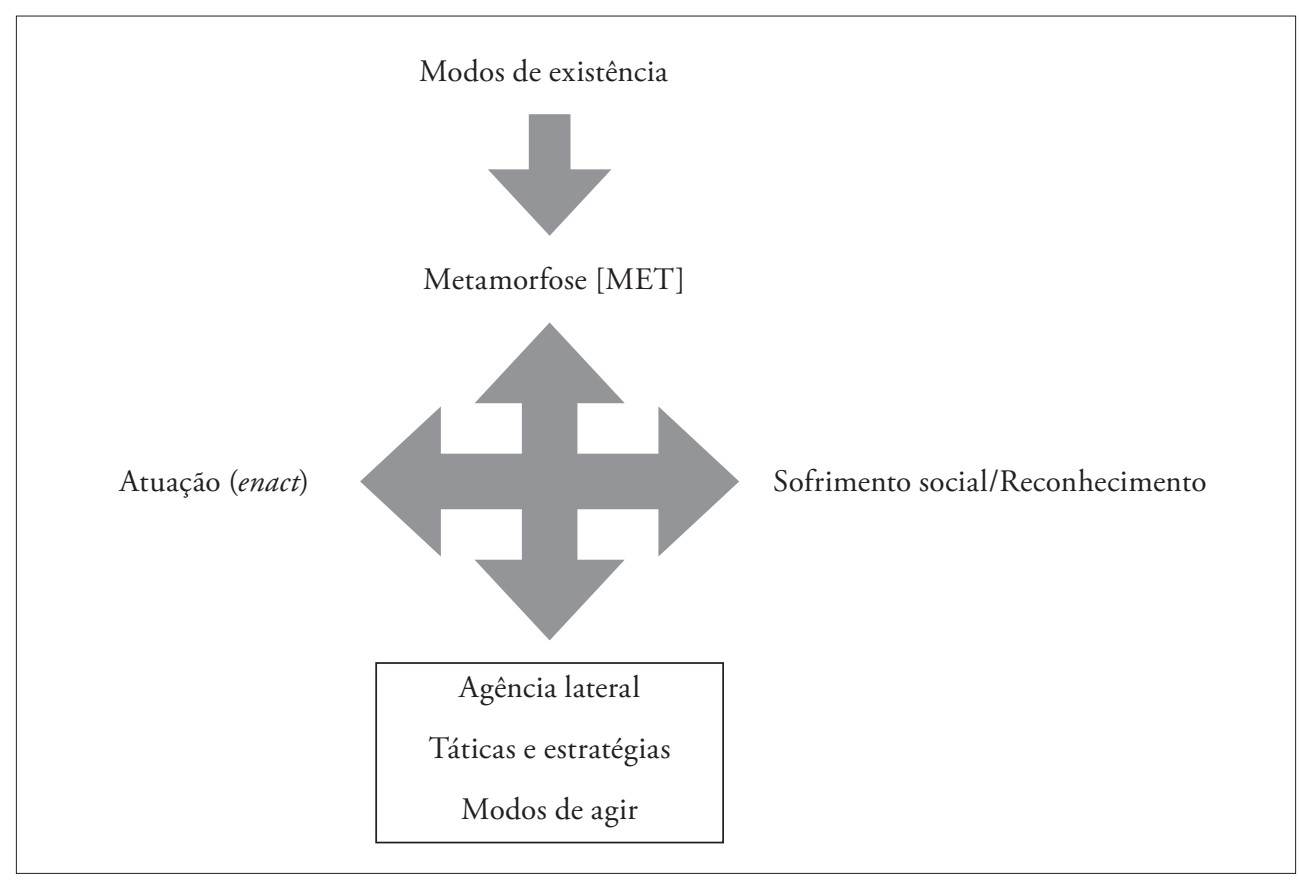

O conceito de modos de existência contempla a ideia de uma incompletude inerente à existência (STENGERS; LATOUR, 2015). Se nada está dado de antemão, existir demanda um trabalho de instauração que permite estabelecer trocas entre diferentes domínios de saber e modos de existência (SOURIAU, 1938).

Dentre os diversos modos de existência catalogados por Latour (2013), o da metamorfose [MET] destaca-se por se referir ao modo de existir dos "seres invisíveis", frequentemente destituídos nas sociedades "modernas" e profundamente instituídos 
e ritualizados naquelas conhecidas como "tradicionais". A terapêutica pode intervir de tal maneira que esses seres invisíveis atuem no sentido de permitir àquele que está em crise emergir e se reformular a partir da manipulação dos idiomas e da negociação com essas entidades, instaurando-as.

Pelo conceito de enact (MOL, 2002), pode-se afirmar que, para compreender e investigar a doença, é imprescindível acessar as práticas que a constituem; o que exige acessar os modos de cuidar, sofrer e agir diante da infinidade de experiências de sofrimento que não se atêm à dimensão simbólica.

Kleinman, Das e Lock (1997) observam que o sofrimento social é derivado daquilo que os poderes político, econômico e institucional fazem sobre as pessoas e da sua influência nas respostas a esses problemas sociais. O cerne dessa experiência residiria justamente em uma relação problemática com uma ordem social que coloca normas e padrôes e situa toda uma gama de pessoas à margem das organizaçôes sociais, tirando-lhes as rédeas de sua própria existência (PUSSETI; BRAZZABENI, 2011).

Já Honneth (2003) atenta para a problemática redução das formas de sofrimento social e descontentamento moral àquelas que já se tornaram visíveis na esfera pública e macropolítica. Com isso, a experiência de reconhecimento social representa uma condição da qual depende o desenvolvimento da identidade humana, ao passo que à negação desse reconhecimento corresponde um senso de uma perda ameaçadora da personalidade. De Certeau (1998), por seu turno, se debruça sobre as microrresistências e microliberdades pensando a mobilização de recursos das mais variadas ordens no incremento de suas táticas e em suas subversóes dos enquadramentos estratégicos. Paralelamente, o conceito de agência lateral (BERLANT, 2011) diz respeito a um modo de manter a consciência dentro do universo do ordinário que ajuda as pessoas a se manterem diante da dificuldade de perpetuar a vida contemporânea. Trata-se de uma experiência peculiar de sustentação de um agir no mundo que não deixa de existir e de se afirmar, ainda que se situe nas margens do social.

Esse conjunto de artefatos teóricos serviu para elucidar os modos de agir (MARQUES, 2016), ou seja, as formas de agência e de instituição da condição de doente mental em âmbito público e privado, embutidos no quadro maior do que se faz do e no vivenciar do sofrimento psíquico.

Tratou-se de pesquisa vinculada a uma pesquisa maior, aprovada sob o parecer no 023-12 do Comitê de Ética de Pesquisa (CEP) do Instituto de Saúde Coletiva, vinculado à Universidade Federal da Bahia, com financiamento de CNPq e Fapesb. 
Todos os participantes anuíram e assinaram o Termo de Consentimento Livre e Esclarecido (TCLE), de acordo com a Resolução 466/2012.

\section{Resultados e Discussão}

\section{A crise enquanto fenômeno: modos de agir, interpretar e apaziguar}

A crise mostrou-se um tema recorrente tanto nas falas quanto na trajetória de nossos interlocutores. Ela se apresenta no nível da ruptura biográfica e dos primeiros passos da condução dos itinerários terapêuticos, mas também como uma experiência frequente, com periodicidade regular e apreensões relativamente sedimentadas acerca do que pode causá-la e de suas manifestações iniciais ou prodrômicas.

Enquanto disparadora da carreira de doente mental, a crise aparece mais em termos de suas causas do que como uma experiência vivida propriamente dita. De modo geral, os participantes tiveram dificuldades em narrar a primeira crise, atendo-se às possíveis causas ou aos seus atos que foram avaliados por outrem como arriscados ou socialmente inadequados, apontando para a necessidade de atendimento em emergências psiquiátricas.

O uso de medicamentos está intimamente ligado ao surgimento das crises, de acordo com o que trazem os participantes. No caso de Bárbara, tanto ela quanto seu pai de santo fazem uma correlação direta entre a medicação psiquiátrica e a crise; porém, para Pai Júlio, a crise pode surgir quando, diante da melhora, Bárbara diminui a ingesta dos medicamentos, tornando-a irregular: "começa sem dormir direito, aí, tem que se envolver logo, porque ou relaxou o remédio, relaxando o remédio, aí, tem que ir fazer dosagens" (Pai Júlio).

Aqui, a crise está ligada a uma displicência, na medida em que a necessidade do uso regular da medicação é relativizada na experiência de melhora do quadro. Essa necessidade, porém, cristaliza-se em uma certa rigidez cotidiana difícil de ser modificada, já que seu oposto imediato é a piora e a consequente crise psíquica que, para ele, exigem um ajuste medicamentoso.

Bárbara também atrela o uso de psicotrópicos à crise, mas no sentido de que estaria neles o bálsamo de seu padecimento. Ela relata que quando "entra em crise" ou "fica deprimida" é imediatamente levada à emergência para "tomar injetável", o que implica uma diminuição imediata dos sintomas daquilo que ela e os demais membros de sua família definem como o "sossega-leão". Enquanto dispositivo 
recomendado e reforçado pelos próprios profissionais do ambulatório, o "sossegaleão" redefine a condução do tratamento ambulatorial, na medida em que sedimenta a lógica do cuidado pautada única e exclusivamente no manejo medicamentoso.

Dell'Acqua \& Mezzina (1991) assinalam que a falta de uma visão integradora e não restritiva da crise traduz-se em propostas terapêuticas fragmentadas que, aliadas a uma escassez de recursos para lidar com os momentos de crise dos usuários, permanecem sem conseguir superar o modelo de referência ao hospital psiquiátrico como ponto final do que não é possível de ser contido nos serviços comunitários. Tal funcionamento reforça a sustentação prática e ideológica do hospital, visto que, diante da opacidade de um fluxo de cuidado que não compreendem, as pessoas em sofrimento e sua rede de apoio recorrem à alternativa que diz respeito à suspensão de situação que se mostra intolerável diante do tecido social.

A porta giratória desloca-se do estatuto de medida avaliativa de serviços em saúde mental e torna-se um mecanismo de obtenção de cuidado que conduz a uma "antecipação da consulta" e póe em ação todo um circuito familiar de atenção à crise. É interessante perceber que a ativação desse sistema prescinde da ocorrência plena da crise, como nos mostra Simone (filha de Bárbara e irmã de Jorge): “[...] assim, quando você sente que 'tá' querendo dar uma 'crisezinha', vai antes por causa da medicação, que, às vezes, também, melhorou, relaxa, entendeu?”

É patente em todos os casos como o retorno ao hospital psiquiátrico quando da irrupção da crise impóe-se diante da falta de recursos comunitários, e não por ser avaliado como a melhor escolha:

Essa noite [primeira crise] eu passei, aqui [na cidade], na maternidade. [...] No Y [nome do hospital], mas lá eu não fiquei internada, só me medicou, depois o médico conversou comigo. [...] Pense aí, em junho eu tive o problema, fui afastada do trabalho. [...] Aí fiquei nervosa, não dormi. Aí 'panhei', fui para [o hospital Y] eu mesma, sozinha. Neste tempo era só 4 cadernetas por dia, Deus me ajudou, que aí eu tive direito a uma. [...] Para matricular e 'dá' continuidade ao tratamento. Aí fiz a caderneta e aí comecei o tratamento. (Candelária)

Com respeito à experiência da crise, dois grupos de fatores parecem ser sinais expressivos de que algo não vai bem e que providências devem ser tomadas: aqueles ligados aos cuidados corporais e aqueles relativos à manutenção das atividades cotidianas:

Um dos jeitos das pessoas perceber que eu não estava legal é porque eu toda hora trocava de roupa e toda hora tomava banho. Toda hora. Isso quando eu náo estava legal. E tinha 
noite, um pouco mais na época, que eu fazia isso, que eu me lembrava das violências sexual aí eu queria limpar com banho, com roupa, pensando que ia resolver a situação com água, ver se resolvia. (Lázaro)

Devido ao desconforto de sair de casa, ela [Bárbara] náo tem conseguido conferir e jogar na loteria e no bicho seu cunhado, que brinca com ela ao dizer que ela "não é mais a mesma" (sic). Além disso, estava sem cozinhar e não costurou ainda as fraldas do enxoval de sua neta, o que ela faz com rapidez sempre que nasce uma criança na família. (Diário de campo).

Para além da sintomatologia, a crise psíquica é vista como causa e consequência de uma suspensão do cotidiano. A necessidade de evitar a crise torna-se, então, muito mais uma espécie de "batalha moral" para preservar sua função na vida social e familiar do que propriamente uma busca pelo apaziguar de um sofrimento, conforme expresso por Candelária:

Falar besteira e fazer besteira é quando a gente não está fazendo as coisas que se aproveitam, né? Alguém tá percebendo que aquela pessoa não está bem e a pessoa tá achando que está bem, né? [...] Então a gente já sabendo que existe isso, cair numa dessa que eu caí... Eu só tinha que ir à luta, para que não acontecesse mais. (Candelária).

O inconformismo diante de uma situação considerada injusta e se perceber como incapaz de enfrentá-la também faz com que a fragilidade se faça reconhecer e se confirme a necessidade de pedir ajuda. Candelária conta-nos sobre sua última crise, quando estava a "discutir com meu genro, [...], e aí quando eu olhava para ele dava vontade de dar uns paus nele. Aí antes que acontecesse, o remédio não 'tava' nem controlando, eu cheguei e fui para o CAPS, pedi socorro".

Lázaro mostra uma experiência similar quando conta que uma de suas crises se deu quando, depois de ser internado em um sanatório espírita, se deparou com a calamidade dos hospitais psiquiátricos de seu estado natal. Do acesso prévio a uma outra lógica de cuidado advém a criação de um senso crítico, de outro platô de exigência em termos de sua qualidade de vida.

Nesses casos, a crise adquire uma faceta benéfica ao abrir espaço para uma reação diante de uma situação opressiva e para a tentativa de solucionar um conflito aparentemente irremediável. Assim, dá aval para a busca por acolhimento, pois permite ao sofrimento tornar-se manifesto exigindo uma resposta daqueles que estão ao redor. Trata-se assim de uma experiência de interrupção que exige uma tomada de posição e expóe a fragilidade da ordem e normalidade, visto que nela as forças instituintes impóem-se ao instituído, delineando rupturas (BAREMBLITT, 2002) e uma abertura para novas formas de vida e existência. 
A rigidez imputada às performances de gênero parece se manifestar nos critérios de delimitação da crise sob o prisma da incongruência com as expectativas sociais. A suposta perda da utilidade ligada ao descumprimento dos afazeres domésticos delineia a experiência de crise das interlocutoras-chave. Trata-se de uma forma de elaboração do cotidiano concatenada à presunçáo de um certo modo de existir enquanto mulher, o que se confirma pelo fato de que essas atitudes "fora da curva" são interpretadas pelos familiares e mesmo pela própria pessoa como um elemento patognomônico.

Essa instituição moral da crise inclui também os homens que parecem sofrer substancialmente com os enquadramentos sociais, com destaque para o tema da periculosidade. Tanto Lázaro quanto Jorge passaram por episódios que entrecruzaram as instituições policial e psiquiátrica. Lázaro traz a seguinte narrativa:

[...] o pessoal que tava morando na rua cometeu um bocado de delito. [...] E aí me levaram pro HCT, mas eu náo cheguei a passar pelo processo, nem passei pela triagem, porque a médica conseguiu interferir.

Jorge passa por um episódio mais marcado e estigmatizante, no qual ele aparece em um telejornal vespertino de amplo alcance popular na cidade de Salvador.

"Ô, tia! Venha cá, que Jorge tá na TV. Vai lá, senão a polícia vai bater." E saí correndo.
[...] Aí levei os remédio tudo, levei documento que ele tem "pobrema". [...] Aí, foi na polí-
cia: "Se soltar ele aí, ele vai meter em alguém e vai ser pior. Melhor levar ele pra dar um
calmante". (Bárbara - mãe de Jorge).

Nesse caso, o lugar de doente mental, embora estigmatizante, permite escapar da violência policial e de uma nova institucionalização, na prisão ou no Hospital de Custódia e Tratamento. O lugar de doente mental, nesse caso, permite a troca de um circuito de violência e exclusão por outro, na medida em que se trata de um intercâmbio entre instituições totais (GOFFMAN, 1961).

$\mathrm{O}$ sofrimento de Jorge ganha notoriedade ao mesmo tempo em que o protagonista é ferido em termos de reconhecimento em uma experiência de desrespeito que coloca em questão sua estima social, suas relaçôes familiares e seu reconhecimento como cidadão detentor de direitos (HONNETH, 2003). A tripla institucionalização compulsória (midiática, policial e psiquiátrica) conduz a uma tripla experiência de desrespeito, cujas chagas se mantêm às custas do "otimismo cruell" (BERLANT, 2011) a que Jorge e sua família estão submetidos.

Vimos ainda que a própria relação estabelecida com os serviços de saúde pode colaborar para a irrupção de crises. Vínculos terceirizados ou temporários de trabalho, 
caracterizados pela precariedade, são motivo de sofrimento para os usuários que se vinculam aos profissionais e depois fazem esse luto solitariamente quando estes são afastados. Além disso, a falta de clareza acerca dos vínculos empregatícios e a hierarquização entre terceirizados e concursados parecem contribuir para a falta de entendimento das relaçóes e do processo de trabalho no serviço.

No CAPS de Lázaro, parece haver uma incongruência entre as expectativas de usuários e profissionais sobre os vínculos de trabalho:

A reunião começa e a sala está lotada. [...] Lázaro, então, acaba fazendo uma fala sobre
a importância de pedir os antigos técnicos de referência de volta, já que é o vínculo com
eles que daria sucesso aos tratamentos em curso e não as medicaçóes. [...] O educador
físico, nesse momento, resolve intervir e explica a situaçáo do corte dos funcionários. De
acordo com o que se sabe, esses funcionários tinham vínculos temporários e, de fato, não
se esperava que pudessem ficar permanentemente. [...] o educador físico diz claramente
que o retorno dos profissionais é inviável e, no final da reuniáo, outra técnica salienta que
é preciso lutar - reafirmando o potencial de luta e reivindicaçáo dos usuários - para que
os aprovados no concurso sejam convocados. (Diário de campo)

Faz-se notar o curso da iatrogenia exercida pela própria gestáo do serviço a partir da saída de profissionais sem um preparo ou uma substituição gradativa, causada tanto pela lógica de concepção do serviço e do atendimento quanto pela precarização da máquina pública, que se impóem como obstáculos à promoção do cuidado.

Podemos aqui estabelecer um paralelismo entre os vínculos estabelecidos com os técnicos de referência, e aqueles estabelecidos nos terreiros. Enquanto no primeiro contexto nos deparamos com a precariedade de recursos para lidar com os aspectos afetivos ligados à relação terapêutica, no segundo, o vínculo é o principal foco de investimento. $\mathrm{O}$ consulente, que busca o pai de santo, procura respostas para suas mazelas e ganha não só acolhimento, mas uma compreensão de suas origens e de seu papel no universo diretamente ligada ao vínculo com o terreiro.

No caso de nossos participantes, vemos que eles se tornam, a um só tempo, membro de uma comunidade e de uma família: pertencem a uma determinada linhagem, tornando-se recheada de novos sentidos sua existência até então marginalizada pela carreira de doente mental e pela desigual relação de classes na sociedade brasileira.

\section{Da crise à metamorfose: as múltiplas faces do acolhimento e reconhecimento da experiência de sofrimento-limite dos filhos de santo}

Os participantes colocam a busca por cuidado nas situaçóes de crise e agudização do sofrimento como algo que deve começar pelo setor oficial; e somente a partir do 
atestado de sua pouca efetividade no problema em curso a procura por um espaço religioso ou sagrado emerge como uma possibilidade real. Mesmo nesses casos, porém, observamos uma circulação e certa simultaneidade na procura dos sujeitos por esses dois setores:

Eu me cuidei primeiro do meu lado psíquico, procurei, fiz tudo isso. Em seguida, coincidentemente, meu babalorixá me... percebeu que eu não estava bem e que chegou a hora de eu concluir mais uma etapa do meu lado espiritual. (Lázaro - Entrevista)

Os dados sugerem que, mesmo com as oscilaçôes hierárquicas entre esses setores de cuidado, há um esforço significativo de busca pela conciliação dessas lógicas. Bárbara, bem como sua família e o próprio pai de santo, frisa a importância de conciliar os cuidados religiosos e médicos e reforçam seu caráter complementar:

Mas foi muito também, a gente cuida de um lado, cuidou do lado material que foi pra o médico, tal, tal, tal, e fazendo as coisas também, "né”? Faz isso, faz aquilo, graças a Deus, foi diminuindo o tempo de "tá" dentro de um hospital, e a medicaçáo que diminuiu, mas, quando relaxa um pouquinho, aí, vai, tem que aumentar de novo. (Entrevista - Pai Júlio)

Em todos os casos, contudo, vemos uma linha de raciocínio comum, a saber: a compreensão da busca por cuidado em espaços religiosos como forma de subverter e escapar ao enquadre do lugar ou da carreira de doente mental (GOFFMAN, 1961). Podemos observar aqui o traçar de uma agência, um desvio nessa carreira cuja largada é dada nos espaços psiquiátricos, de modo a deslocar-se da sujeiçáo e estigmatização que por vezes ocorre no setor oficial de cuidado em saúde mental. Como nos aponta Estroff (1981), a inserção religiosa permite escapar do circuito da loucura, visto que oferece suporte interpessoal e a reconfiguração da rotina por meio da proposição de novas atividades fora do enquadramento clínico formal.

Se observamos mais atentamente como funciona o acolhimento a pessoas em sofrimento na comunidade religiosa a que Lázaro e Candelária se vinculam, podemos compreender melhor a singularidade dessa lógica.

Pai Ernestino, pai pequeno ${ }^{2}$ do terreiro de Pai Gerônimo, conduz sessóes de caboclo quinzenalmente em sua casa na periferia de Salvador. Nessas sessóes, os filhos de santo iniciados no terreiro de Gerônimo entram em transe e recebem os caboclos, que ofertam consultas à comunidade:

Pai Ernestino: "Quando eu encaminho pra ele [pai de santo], é porque é pra passar... dar um bori. Bori pra ajudar, é tudo com ele. O bori é pra saber se a pessoa vai fazer feitura ou não." 
Entrevistadora: “Ah, sim! Então se tiver necessidade de um bori, o senhor já...”

Pai Ernestino: "Encaminha pra ele."

Entrevistadora: "E aí, essa necessidade do bori, quem diz é o caboclo?"

Pai Ernestino: "O caboclo mesmo fala que é pra procurar o Gerônimo, que a parte dele, ele já fez, e que a parte que tem pra fazer já não é mais dele. [...] Porque o caboclo não vai dar bori em ninguém.[...] 'Cê sabe que o caboclo não pode dar bori. Quem dá é o pai de santo, né?’ Dá o iniciamento aqui em minha casa e depois vai pra roça. Inicia direto, depois." (Entrevista - Pai Ernestino)

Se tomarmos a definição de linha de cuidado enquanto não só uma estratégia de ação que atravessa diversos níveis de atenção, mas enquanto um processo dinâmico e sistêmico de produção da saúde a partir de redes macro e microinstitucionais em que a atenção e o cuidado pautam-se nas necessidades do usuário (MALTA; MEHRY, 2010); conseguimos perceber que a sua elaboração dentro dos espaços religiosos aparece como algo recorrente, na qual são avaliados o grau de complexidade e as intervençôes que serão necessárias, e então o sujeito passa a enquadramentos específicos dentro da mesma instituição.

No relato acima vemos, inclusive, a utilização do verbo "encaminhar", que já é um jargão comum entre profissionais de saúde e pelo público em geral. Percebemos aqui a apropriaçáo de uma relaçáo com os serviços de saúde e ressignificação semântica do encaminhamento, que não mais se refere a um movimento de externalização, mas a uma inserçáo ainda mais profunda dentro da comunidade religiosa. A rede de cuidado é acordada e estabelecida entre as lideranças religiosas, entidades e deuses, sendo sempre destes últimos a palavra final.

Tanto no caso de Lázaro quanto no de Bárbara, todavia, percebemos que essa hibridização do cuidado em saúde mental passa menos pela negociação com os serviços ditos oficiais de saúde do que pela construção compartilhada de um conhecimento entre os sacerdotes e seus discípulos, em que noçôes e conceitos biomédicos, psicológicos, ritualísticos e cosmogônicos são reagregados, de forma que um itinerário terapêutico e o pertencimento à comunidade religiosa tornam-se possíveis:

Agora, tudo compartilhado com a saúde. O meu babalorixá entra em contato pra saber como é que tá o meu medicamento, porque tá tudo certinho, tudo normal. É tudo compartilhado, é tudo compartilhado e é isso que... a minha vida é tấo grande que se isso chegasse aos usuários de saúde mental... como compartilhar a sua religião com o seu tratamento? Porque comigo tá extremamente dando certo. (Lázaro - Entrevista). 
O acolhimento a pessoas em crise, portanto, ao mesmo tempo em que caracteriza, altera o cotidiano do terreiro, como se o ordinário de um ilê se estabelecesse no movimento entre o caos e ordenamento. Vemos, assim, as lideranças das comunidades de terreiro como estando para além de um guardião ou gatekeeper (THOMPSON; HUNT; ISSAKIDIS, 2004), enquanto um agente ativo na linha de frente na busca e acesso de cuidados em saúde e que não necessariamente é um profissional de saúde.

Uma mãe ou pai de santo - como outras lideranças religiosas - podem corresponder plenamente a esse conceito, mas não se reduzem a ele. Esse grau de comprometimento de cuidado, mais do que identificar, diz respeito a um necessário esforço de apaziguar a aflição, mesmo sem qualquer tipo de suporte ou estrutura, o que nos remete a um projeto maior de vida que esses sacerdotes possuem e à manutenção de uma comunidade que se sustenta com base na dissolução da dor.

\section{Instituindo a desinstitucionalização: uma reflexão sobre o papel dos terreiros na atençáo psicossocial}

Um elemento que nos chamou bastante a atenção foi a emergência da internação ou do atendimento intensivo em emergências psiquiátricas enquanto uma experiência tabu. Com exceção de Lázaro, os demais participantes tiveram grande dificuldade não só de rememorar, mas de falar a respeito do que viveram nas suas experiências manicomiais, independentemente da duração.

Dona Candelária, por exemplo, quando conta de seu primeiro atendimento na emergência geral de sua cidade, apenas consegue fazê-lo ao ler um documento emitido um ano depois pela Santa Casa, que narra esse primeiro episódio. Espoleta, seu erể, em uma situação ritual, desponta como o porta-voz da carreira de doente mental de Candelária quando convoca a pesquisadora e exige que a "doutora psiquiatra conheça a história da loucura da menina” (Diário de Campo).

Dessa posiçáo intermediária entre a plena consciência e o transe, a narrativa de institucionalização torna-se viável por meio da sua elaboração a partir de outro sujeito de enunciação que organiza a história que Candelária não é considerada capaz de desenvolver. A chegada em crise ao hospital psiquiátrico parece conter algo impassível de registro ou interpretação simbólica, mostrando-se pertinente aventar uma espécie de foraclusão dessas experiências.

O termo "foraclusão" designa um mecanismo específico da psicose por meio do qual um significante fundamental é rejeitado ou excluído do universo simbólico do 
sujeito, de forma que "é a relação com o objeto que se entrevê no limite" (LACAN, 1988, p. 23). Butler (2014), contudo, póe em xeque o estatuto de a-historicidade e universalidade da foraclusão, visto que o não simbolizável seria sempre relativo a um domínio linguístico que legitima sua foraclusão, de onde se contempla seu caráter político que sedimentaria a constituição desse domínio de um "fora" não passível de ser vivido e ininteligível (BUTLER, 1993, p. 22). Sendo assim, a seleção do que é ou não simbolizável passa inextrincavelmente por um espectro de relaçôes de poder que vão repercutir na constituição dos sujeitos e possuem importantes repercussóes identitárias.

A inserção de Lázaro enquanto usuário militante na luta antimanicomial forneceu-lhe um contexto para abrir uma espécie de portal crítico e político para que os significantes manicomiais e da crise emudecida pudessem finalmente falar, no sentido daquilo que Butler (1993) coloca como a necessidade de trazer esses significantes de volta ao simbólico que subsidia nossas relaçôes sociais, permitindo sua manipulação e ressignificação. A inserção ativista de Lázaro permitiu a ele dar nome à vacuidade subjetiva perpetrada pelo desrespeito (HONNETH, 2007, p. 105-106) engendrado na instituição psiquiátrica.

Enquanto a trajetória de chegada ao Candomblé e todos os elementos dessa imersão religiosa são apresentados pelos interlocutores-chave (com exceção de Jorge) com riqueza de detalhes e de forma organizada e sincrônica, a trajetória do tratamento em saúde mental emerge de forma caótica, repleta de contradiçôes e incongruências, quando não de enormes lacunas sobre as quais pouco se consegue elaborar algo.

Vemos que os serviços de saúde mental e os espaços religiosos lidam por vias diferentes com a aflição e seu apaziguamento. As lógicas muitas vezes são opostas, pois se certos enquadramentos religiosos abrem margem para a recepção e manifestação dos seres invisíveis ligados à crise; diversos serviços de saúde mental, cuja prática em muito se sustenta na formação qualificada pelo triângulo "psi", pautam-se na evocação da interioridade, seja ela compreendida como o cérebro ou o inconsciente.

Não está em jogo tomar o modus operandi de uma agência terapêutica pelo da outra, mas de manter as portas abertas também para esses seres que, se são incompatíveis com a racionalidade científica ou psicológica, atuam e modificam a vida e a experiência de usuários e seus familiares. Isso porque o fim do manicômio por si só não garante a desinstitucionalização em saúde mental, na medida em que subjaz a serviços abertos como os ambulatórios uma 


\begin{abstract}
[...] necessidade perversa de uma organização social à qual é difícil renunciar: o ambulatório de higiene mental, suave e tecnificado, e a secção manicomial, fedida e violenta, representam duas faces da mesma moeda. [...] Basicamente, existe um preconceito de fundo: é aquele sobre a suposta não recuperação do doente mental. (VENTURINI, 2016, p. 31, grifos do autor).
\end{abstract}

Além disso, há de se reconhecer e combater uma "lógica manicomial" que se expressa e ratifica em práticas de cuidado capturadas por essa forma de pensamento, "reproduzindo-a e impedindo a construção de vida para além do hospital, dos muros institucionais e dos serviços de saúde em geral” (AMORIM; DIMENSTEIN, 2009, p. 196), atualizando-se contemporaneamente.

Por outro lado, as instituiçóes não são algo necessariamente ruim, na medida em que a vida social humana está, desde o seu início, embebida em diversos aparatos institucionais. Seguindo esse raciocínio, vemos que a institucionalização religiosa, quando náo se pretende totalizadora e opressiva, pode contribuir para a consolidação de um projeto mais amplo de desinstitucionalização em saúde mental.

E é precisamente por meio dessa acepção que resgatamos a instituição religiosa representada pela interlocução dos modos de existência da metamorfose e da reprodução enquanto um processo social que náo pode ser qualificado de antemão. $\mathrm{O}$ fato de atuarem com referências e signos distintos de modo algum impede sua aliança; pois é esse incessante intercâmbio de uma infinidade de signos, significados e práticas entre diferentes atores e instituiçóes que permite levar adiante a bandeira psicossocial. Por esse prisma, talvez seja possível falar que ocorre nesses locais outro vínculo institucional. Não mais aquele totalizante e totalitário ligado à carreira de doente mental, mas outro, talvez mais ligado ao processo de formaçáo dos hábitos e de inclusão em um determinado grupo social, o que pressupóe mecanismos de historicidade e controle inerentes a qualquer sociedade (BERGER; LUCKMANN, 2008).

Vejamos, a título de exemplo, o momento em que Espoleta refere-se à Federação de Terreiros de Candomblé de seu município e nos diz que Candelária agora está melhor porque "seu santo tem registro na Federaçáo". Isso nos mostra a importância do reconhecimento institucional para atestar a eficácia terapêutica do terreiro.

A institucionalização do terreiro conduz a uma institucionalização das relaçôes que ali se estabelecem, reforçam e reiteram sua legitimidade, assegurando seus filhos e sacerdotes; o que também contribui para o incremento dos rituais, bem como a 
eficácia e efetividade dos mesmos, já que, para além da melhora, toda uma série de relaçóes sociais é mobilizada e transformada nesses contextos.

Se, para Venturini (2016), é no entrecruzamento entre diversos tempos e espaços que é possível perpassar os três níveis estratificados da desinstitucionalização habilitação psicossocial, inclusão social e promoção social -, Lázaro confirma o poder dessa institucionalização instituinte quando insere o serviço substitutivo em um potente continuum institucional que lhe permitiu obter apoio social e a outros atores:

Chico Xavier, Irmã Dulce, Mãe Menininha do Gantois, é, esse pessoal da umbanda, também foram muito importantes. Hoje o pessoal do serviço substitutivo... Ser ouvido, ser ouvido, como é, me sentir um cidadão, saber quem sou eu. (Lázaro)

Por outro lado, os serviços substitutivos também podem auxiliar a reduzir o estigma e rever algumas preconcepçôes ligadas ao instituído nesses espaços religiosos. Vemos, por exemplo, que se Pai Júlio não se furta a acolher Jorge em momentos de crise, contudo, há uma circunscrição moral acerca de drogas ilícitas que impedem que o seu uso seja pensado fora do enquadramento da punibilidade a que esse tipo específico de substâncias é referido no senso comum. Nesse caso, uma interlocução com detentores de outros discursos que escapem ao enquadre midiático-policialesco pode esclarecer dúvidas, rechaçar estereótipos e preconceitos, como também pensar coletivamente em formas de acolhimento nessas situaçóes. Esse processo exige a convocação e mobilização de novos (e mesmo velhos) atores que podem, em conjunto, contribuir para o incremento de outras formas de cidadania e existência.

\section{Conclusão}

Pudemos verificar que a crise se apresenta como uma experiência pessoal significativa, ainda que sua definição seja mais substancialmente marcada pela valoração das atitudes socialmente reprováveis que pode elicitar, e pela necessidade de rápida contenção, do que pela sua apreensão subjetiva. Observamos ainda que, por vezes, os serviços de saúde que acolhem essas pessoas podem não só ter procedimentos inadequados e parcas condiçôes de funcionamento, como também podem ter efeitos iatrogênicos devido à incidência de seus próprios mecanismos burocrático-institucionais, que vão na contramão na atenção psicossocial.

Observamos, no entanto, que o fato de serem adeptos do Candomblé oferece aos interlocutores mais uma esfera de cuidado e uma possibilidade de manejar outros 
modos de existência que mudam significativamente a elaboração do seu cotidiano. $\mathrm{Na}$ medida em que podem elaborar outra narrativa para si, nossos interlocutores nos mostram como paulatinamente com a imersão religiosa no Candomblé ocorre uma interessante transmutação.

Para além de uma instância terapêutica, o terreiro é pensado como comunidade. Nele, a aflição é reconhecida e tratada, mas como observamos em nosso campo, essa remissão do sofrimento presta-se a uma concepção mais ampla de si e do mundo que lhes permite contribuir com o funcionamento e sobrevivência da comunidade. De uma posição de demanda por acolhimento, nossos partícipes passam a se ver como pessoas que passariam a ter, então, responsabilidades com aquela instituição, tornando-se um membro de uma comunidade religiosa com direitos e deveres, ou seja, mais um componente na rede de circulação das dádivas e do cuidado.

Por fim, reforçamos a necessidade de construção de oficinas e espaços de construção compartilhada de conhecimento em saúde mental, como também de dar atenção ao circuito de terreiros não patrimoniados, sem reconhecimento e investimento público. Se o parco financiamento público da saúde e as difíceis condições de trabalho são, em termos práticos, inevitáveis, vemos que há todo um exercício tático e de reversão lateral das adversidades em prol do cuidado da população; de maneira que se faz mister vislumbrar a oferta de um espaço minimamente dialógico para que essas lideranças religiosas possam compartilhar as agruras de seu cotidiano de cuidado e trazer também suas perspectivas àqueles que projetam uma saúde integral, equitativa e participativa. ${ }^{4}$

\section{Referências}

AMORIM, A. K.de M. A.; DIMENSTEIN, M. Desinstitucionalização em saúde mental e práticas de cuidado no contexto do serviço residencial terapêutico. Ciênc. saúde coletiva, v. 14, n. 1, p. 195-204, 2009.

BAREMBLITT, G. F. Compêndio de Análise Institucional e outras correntes: teoria e prática. 5 ed. Belo Horizonte: Instituto Félix Guattari, 2002.

BERGER, P. L.; LUCKMANN, T. A construção social da realidade. 29 ed. Petrópolis: Vozes, 2008.

BERLANT, L. Cruel optimism. Durham \& London: Duke University Press, 2011.

BUTLER, J. Bodies that matter. On the discursive limits of "sex". New York: Routledge, 1993. . Regulaçóes de gênero. Cadernos Pagu, v. 42, p. 249-274, 2014. 
DE CERTEAU, M. A invenção do cotidiano: artes de fazer. 3 ed. Petrópolis: Vozes, 1998.

DELEUZE, G.; GUATTARI, F. Mil platôs: capitalismo e esquizofrenia, v. 1. São Paulo: Ed. $34,2007$.

DELL'ACQUA, G.; MEZZINA, R. Resposta à crise - estratégia e intencionalidade da intervenção no serviço psiquiátrico territorial. In: DELGADO, J. (Org.). A loucura na sala de jantar. São Paulo: Resenha, 1991, p. 53-79.

ESTROFF, S. Making it crazy. An ethnography of psychiatric clients in an American community. London, Berkeley, Los Angeles: University of California Press, 1981.

FERIGATO, S. H.; ONOCKO-CAMPOS, R. T.; BALLARIN, L. G. S. O atendimento à crise em saúde mental: ampliando conceitos. Revista de Psicologia da UNESP, v. 6, n. 1, p. 3144, 2007.

GOFFMAN, E. Manicômios, prisóes e conventos. São Paulo: Perspectiva, 1961.

HONNETH. A. Luta por reconhecimento: a gramática moral dos conflitos sociais. São Paulo: Editora 34, 2003.

. Sofrimento de indeterminação. São Paulo: Singular, 2007.

INGOLD, T. Jornada ao longo de um caminho de vida: mapas, descobridor-caminho e navegação. Religião e Sociedade, v. 26, n. 1, p. 76-110, 2005.

KLEINMAN, A.; DAS, V.; LOCK, M. (Org.). Introduction. In: Social suffering. Berkeley, Los Angeles, London: University of California Press, 1997, p. ix-xxvii.

LACAN, J. Seminário 3: as psicoses. 2 ed. Rio de Janeiro: Jorge Zahar, 1988.

LATOUR, B. An inquiry into modes of existence: an Anthropology of the Moderns. Cambridge, London: Harvard University Press, 2013.

LEAL, E. M.; DELGADO, P. G. G. Clínica e cotidiano: o CAPS como dispositivo de desinstitucionalização. In: PINHEIRO, R. et al. (Orgs.). Desinstitucionalização na saúde mental: contribuiçôes para estudos avaliativos. Rio de Janeiro: CEPESC-IMS/LAPPIS: ABRASCO, 2007, p. 137-154.

MALTA, D. C.; MERHY, E. E. O percurso da linha do cuidado sob a perspectiva das doenças crônicas não transmissíveis. Interface (Botucatu), v. 14, n. 34, p. 593-606, 2010.

MARQUES, T. P. Modos de agir: a doença mental nas tramas históricas. In: NEVES, J. (Org.). Quem faz a História. Ensaios sobre o Portugal contemporâneo. Lisboa: Tinta da China, 2016, p. 71-82.

MOL, A. The body multiple: ontology in medical practice. Durham \& London: Duke University Press, 2002.

NICÁCIO, M. F. (Org.). Desinstitucionalização. São Paulo: Hucitec, 1990. 
NUNES, M. O.; TORRENTÉ, M. Estigma e violências no trato com a loucura: narrativas de centros de atenção psicossocial, Bahia e Sergipe. Revista de Saúde Pública, v. 43, p. 101-108, 2009. PORTUGAL, C. M. Entre enredos de axé e redes de saúde mental: uma cartoetnografia de adeptos do Candomblé em processo de desinstitucionalização. 328 f. Tese (Doutorado em Saúde Pública) - Instituto de Saúde Coletiva, Universidade Federal da Bahia, Salvador, 2018.

PORTUGAL, C. M.; NUNES, M. de O. Entre o dito e o feito: uma análise preliminar da questão da aflição e do sofrimento nos estudos antropológicos sobre o Candomblé. Physis, v. 25, n.4, p.1313-1333, 2015.

PUSSETI, C.; BRAZZABENI, M. Sofrimento social: idiomas da exclusão e políticas do assistencialismo. Etnográfica, v. 15, n. 3, 2011, p. 467-478.

SOURIAU, É. Avoir une âme: essai sur les existences virtuelles. Paris: Les Belles Lettres, 1938.

STENGERS, I.; LATOUR, B. The sphinx of the work. In: SOURIAU, É. The different modes of existence. Minneapolis: Univocal Publishing, 2015, p. 11-94.

VENTURINI, E. A linha curva: o espaço e o tempo da desinstitucionalização. Rio de Janeiro: Fiocruz, 2016.

THOMPSON, A.; HUNT, C.; ISSAKIDIS, C. Why wait? Reasons for delay and prompts to seek help for mental health problems in an Australian clinical sample. Social Psychiatry and Psychiatric Epidemiology, v. 39, n. 10, p. 810-817, 2004.

\section{Notas}

${ }^{1} \mathrm{O}$ otimismo cruel de que fala Berlant concerne a uma experiência social que data do final do séc. XX, aprofundando-se nos dias de hoje, na qual desejar algo configura exatamente o obstáculo ao seu desenvolvimento pessoal. Subjaz a isso uma fantasia de "boa vida" que inclui elementos morais, econômicos e íntimos, mas que claramente se mostram frágeis na realidade e que se busca a todo custo manter e sustentar. ${ }^{2}$ Espécie de liderança secundária, responsável pelo terreiro no caso de ausência do pai ou mãe de santo.

${ }^{3}$ Pode designar os orixás Ibejis, como também uma espécie de espírito infantil que atua como porta-voz do orixá ou ainda desempenhar uma funçấo de trânsito entre a experiência do transe e a consciência plena.

${ }^{4}$ C. M. Portugal foi responsável pela concepção, delineamento, análise e interpretação dos dados; redação e revisão crítica do artigo. M. O. Nunes foi responsável pela concepção, análise e interpretação dos dados; revisão crítica e aprovação da versão final do artigo. M. F. C. Coutinho responsabilizou-se pela redação e revisão crítica do artigo. 


\section{Abstract}

Paths of axé in the search for care: $a$ preliminary analysis of the crisis experience of candomble followers in the process of deinstitutionalization in mental health

This paper aimed to address the experience of the crisis in mental health from the cartoethnography of the existential territories and daily practices of care for candomblé followers in the process of deinstitutionalization in mental health in Salvador, Brazil, and adjacent areas. For these purposes, the cartoetnographic theoretical-methodological approach was used. The research involved unstructured interviews coupled with participant observation in the ethnographic molds in the participants' daily living spaces. Data analysis was based on ethical categories focused on the process of deinstitutionalization and on a second reading supported by what we proposed as the "cartoethnographic matrix of lines of thought". We find that the experience of crisis is very present in the trajectories of the interlocutors, which marks are the interruption of daily life, their moral value and the call (sometimes tacit) of the support network. From the narrative viewpoint, care in emergency rooms and / or psychiatric emergencies is symbolically emptied and even foracluted, while the care support in the terreiros is symbolically rich and offers an horizon for other interpretations and (re)creations of existence; this highlights their importance as institutions that can contribute to the deinstitutionalization in mental health of those who resort to them.

Keywords: cartoethnography; crisis; mental health; care; deinstitutionalization. 